\title{
Congenital central hypoventilation syndrome with hyperinsulinism in a preterm infant
}

\author{
Ulrike Hennewig · Berit Hadzik · Markus Vogel • \\ Thomas Meissner · Timm Goecke - Hartmut Peters · \\ Georg Selzer · Ertan Mayatepek · Thomas Hoehn
}

Received: 17 December 2007/ Accepted: 18 February 2008/Published online: 14 March 2008

(C) The Japan Society of Human Genetics and Springer 2008

\begin{abstract}
Congenital central hypoventilation syndrome (CCHS), a rare disorder typically presenting in the newborn period, results in over $90 \%$ of cases from PHOX2B polyalanine repeat mutations. It is characterized by alveolar hypoventilation, symptoms of autonomic nervous system dysregulation, and in a subset of cases Hirschsprung's disease and, later, tumors of neural crest origin. We describe a preterm infant with severe phenotype of CCHS and hyperinsulinism. A novel de novo heterozygote missence mutation (Gly68Cys) in the PHOX2B gene could be identified. Based on the observation of three patients presenting with the combination of congenital
\end{abstract}

U. Hennewig · B. Hadzik · M. Vogel - T. Meissner .

E. Mayatepek · T. Hoehn

Department of General Pediatrics, University Hospital

Duesseldorf, Duesseldorf, Germany

U. Hennewig

Department of Pediatric Oncology,

Hematology and Clinical Immunology,

University Hospital Duesseldorf, Duesseldorf, Germany

T. Goecke

Institute of Human Genetics and Anthropology,

University Hospital Duesseldorf, Duesseldorf, Germany

H. Peters

Institute of Medical Genetics, Charité University Medicine, Berlin, Germany

G. Selzer

Department of Pediatric Intensive Care Medicine,

Klinikum Bremen, Bremen, Germany

T. Hoehn ( $\square)$

Department of General Pediatrics, Heinrich-Heine-University,

Moorenstr. 5, 40225 Duesseldorf, Germany

e-mail: thomas.hoehn@uni-duesseldorf.de hyperinsulinism and CCHS, hyperinsulinism might represent an additional clinical feature of CCHS.

Keywords Congenital central hypoventilation syndrome . Ondine's curse - Hyperinsulinism · Preterm infant .

PHOX2B gene

\section{Introduction}

Congenital central hypoventilation syndrome (CCHS) is a rare disorder with about 300 patients reported worldwide (Weese-Mayer and Berry-Kravis 2004). The syndrome comprises absence of adequate control of respiration with decreased sensitivity to hypercapnia and hypoxia. Clinical onset occurs in the first few postnatal days in most patients, in the absence of neuromuscular or lung disease or identifiable brain stem lesion. Infants with CCHS typically show adequate ventilation while awake, but hypoventilation with normal respiratory rates and diminished tidal volume during sleep. More severely affected infants hypoventilate both when awake and asleep (Weese-Mayer et al. 1999). CCHS has been reported in association with aganglionic megacolon (Hirschsprung's disease) in $\sim 15$ $20 \%$ (Weese-Mayer and Berry-Kravis 2004; Croaker et al. 1998 ) and with tumors of neural crest origin: ganglioneuroma, neuroblastoma, and ganglioneuroblastoma, in $\sim 5 \%$ of patients with CCHS (Rohrer et al. 2002).

CCHS also occurs with symptoms of diffuse autonomic nervous system dysregulation, including decreased heart rate variability, pupillary abnormality, esophageal dysmotility, decreased perception of discomfort, sporadic profuse sweating episodes and decreased basal body temperature (Weese-Mayer and Berry-Kravis 2004). Mutations in the PHOX2B gene have been identified to be the underlying 
genetic cause (Amiel et al. 2003; Matera et al. 2004). We report here the case of a preterm infant with CCHS and hyperinsulinism caused by a formerly unknown de novo mutation in the PHOX2B gene.

\section{Case report}

The patient was born by Cesarean section after $33+2$ weeks of gestation due to abnormal cardiotocogram findings. Birth weight was $1,890 \mathrm{~g}$; there were no risks of maternal infection, a course of antenatal steroids had been given. Postnatally, the infant had an insufficent respiratory drive and was intubated and ventilated. Following extubation, the patient showed episodes of apnea and bradycardia while on nasopharyngeal continuous positive airway pressure (CPAP). Episodes with sufficient respiration were followed by episodes with intubation and assisted ventilation (for details, see Fig. 1). Intermittently, the female infant showed episodes of profuse sweating. Furthermore, pronounced dysfunction of swallowing with absent sucking reflex was observed. Recurrent hypoglycemia became evident at the age of 6 weeks, and elevated insulin levels during hypoglycemia confirmed the diagnosis of hyperinsulinism [on initial presentation: glucose $27 \mathrm{mg} /$ dl $(1.5 \mathrm{mmol} / \mathrm{l})$, insulin $9.2 \mathrm{mU} / \mathrm{l}$, ratio 6.1 ; during the course: glucose $16 \mathrm{mg} / \mathrm{dl}(0.89 \mathrm{mmol} / \mathrm{l})$, insulin $19.9 \mathrm{mU} / \mathrm{l}$, ratio 22.4; C-peptide, glucagon, cortisol, and TSH were within the normal range, T4 was slightly decreased, free fatty acids increased]. Treatment with diaxozide and carbohydrate-enriched diet was successful in avoiding hypoglycemia and could be discontinued at the age of
4 months. Ultimately, the infant had to be ventilated on a permanent basis and tracheostomy was performed at the age of 3 months.

There was no evidence for a molecular defect as frequently detected in congenital hyperinsulinism (e.g., SUR1 or Kir6.2). However, DNA sequencing revealed a previously not described heterozygote transversion in exon 1 (c.202G > T, cDNA based on GenBank accession number NM_003924), which resulted in a substitution from glycin to cysteine (Gly68Cys) in the PHOX2B gene (Fig. 2). This mutation could neither be found in the parents nor in the brother of the patient; biological parenthood was confirmed. Therefore, it is likely to be a de novo mutation, although a germ line mosaicism cannot be excluded. The remainder of diagnostic tests and imaging (Palladino et al. 2008) showed no further abnormalities. At the age of 9 months, our patient was discharged from hospital and died a few weeks later from respiratory causes at home.

\section{Discussion}

The combination of CCHS with Hirschsprung's disease in an extremely preterm infant has been described previously (Bajaj et al. 2005). In our patient with profound and prolonged respiratory insufficiency, no associated disease like Hirschsprung's disease, that might give further clues towards CCHS, was existent. At a gestational age of $33+2$ weeks, our patient did not represent an extremely preterm infant, which made it difficult to assess whether intermittent respiratory insufficiency was still due to the condition of prematurity. The patient also showed
Fig. 1 Graphic presentation of episodes of ventilation, hypoglycemia, and autonomic dysregulation including duration and the day of life of occurrence

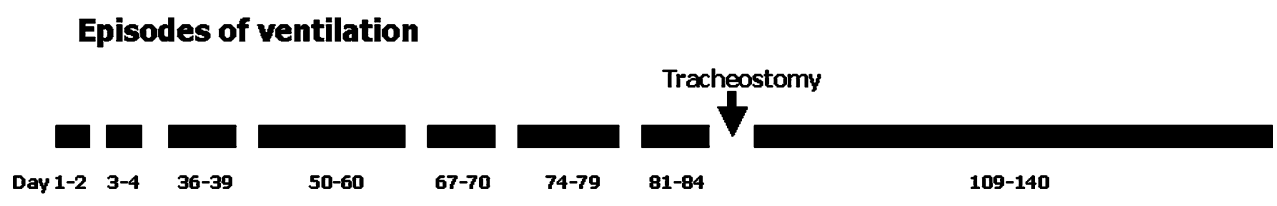

Hypoglycemia

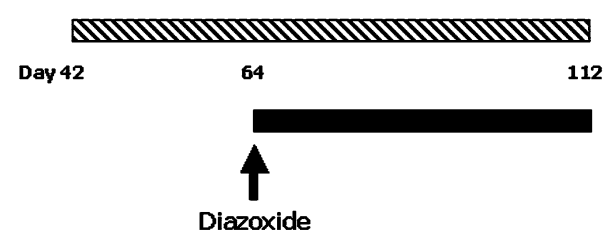

Autonomic dysregulation

including profuse sweating, difficulties swallowing

Day 1

140 


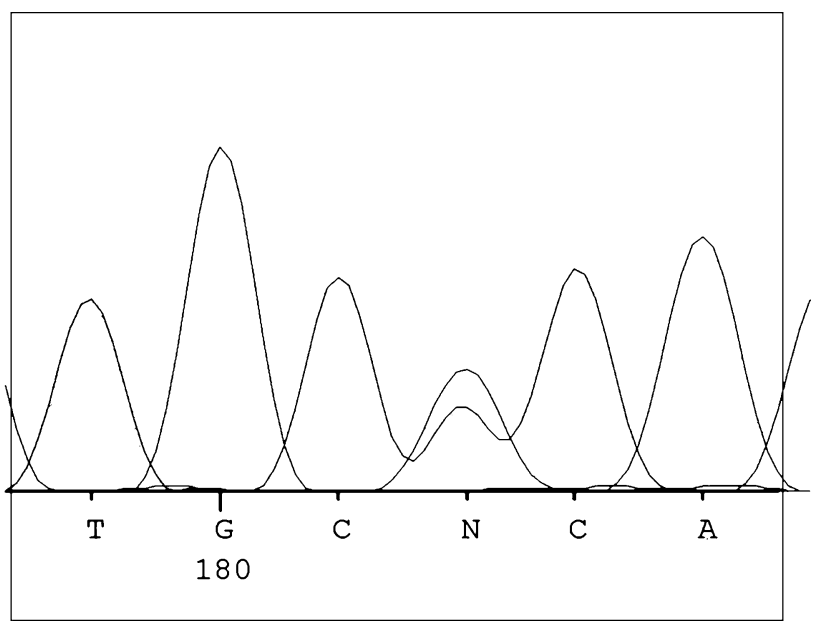

Fig. 2 Heterozygous transversion in exon 1 at position c.202G $>$ T (the opposite strand is shown: $\mathrm{C}>\mathrm{A}$ ) results in a substitution from glycine to cysteine (Gly68Cys) in the PHOX2B protein

symptoms of autonomic nervous system dysregulation such as esophageal dysmotility. As premature infants often have problems like recurrent central apneas and feeding intolerance, diagnosing CCHS in these patients is challenging. Furthermore, our patient presented with hyperinsulinism. Although congenital hyperinsulinism has been described in one patient with severe CCHS (Meissner et al. 2001), hyperinsulinism is not considered a typical associated feature. In addition to the relative dysfunction in the enteric nervous system seen in CCHS, more complex pathophysiological mechanisms may also result in persistent hyperinsulinism. As diffuse autonomic nervous system dysfunction is frequently seen in CCHS, pancreatic islets cells could also be affected, which are richly innervated by parasympathetic, sympathetic and sensory nerves. Several different neurotransmitters are stored within the terminals of these nerves, both the classical neurotransmitters, acetylcholine and noradrenaline, and several neuropeptides (Ahren 2000). We know from other investigations that PHOX2B delineates an uninterrupted chain of sensors and neurons involved in the integration of central and peripheral chemoreception, including carotid bodies, chemoreceptor afferents, chemoresponsive projections to the ventrolateral medulla, and central chemoreceptors (Stornetta et al. 2006). This is supported by both loss- and gain-of-function experiments which suggest that the transcription factor PHOX2B coordinates quantitative and qualitative aspects of neurogenesis no matter if cholinergic, catecholaminergic, or serotonergic neurons are concerned (Dubreuil et al. 2000, 2002). Norepinephrine and epinephrine-deficient mice have been reported to be hyperinsulinemic and to have lower blood glucose (Ste Marie and Palmiter 2003). These experiments have been performed in dopamine beta-hydroxylase-null $\left(\mathrm{Dbh}^{-1-}\right)$ mice. Knowing that dopamine beta-hydroxylase is coexpressed with PHOX2B would easily explain coexisting CCHS and hyperinsulinism with resulting hypoglycemia (Trochet et al. 2005; Zhu et al. 2005). Numerous interactions of PHOX2B with other genes have been described: RET (Proto-oncogene tyrosine-protein kinase receptor ret precursor), GDNF (Glial cell line-derived neurotrophic factor precursor), EDNRB (Endothelin B receptor precursor), ASCL1 (Achaete-scute homolog 1), DBH (Dopamine beta-hydroxylase precursor), TH (Tyrosine 3-monooxygenase), NEUROG2 (Neurogenin 2), TLX3 (T-cell leukemia homeobox protein 3), SOX10 (Transcription factor SOX-10), and EDN3 (Endothelin-3 precursor). The closest interaction shown so far has been described for dopamine beta-hydroxylase.

PHOX2B polyalanin repeat expansion mutations have been identified in about $90 \%$ of CCHS, a small subset of patients has alternative, nonpolyalanin repeat expansion mutations (Amiel et al. 2003; Matera et al. 2004). Familial cases of CCHS are reported in which the pattern of inheritance is autosomal dominant with reduced penetrance (Matera et al. 2004; Weese-Mayer et al. (2003), but most mutations-like in our patient-occur de novo (Amiel et al. 2003; Matera et al. 2004; Weese-Mayer et al. 2003). The severity of the phenotype augments with increasing polyalanine expansion size and non-polyalanine repeat mutations result in even more severe phenotypes (Matera et al. 2004; Berry-Kravis et al. 2006). Furthermore, patients with non-polyalanin mutations show increased prevalence of autonomic nervous system dysregulation, Hirschsprung's disease and malignant tumors of the sympathetic nervous system (Trochet et al. 2005; Berry-Kravis et al. 2006). Our patient with a missense mutation showed symptoms of autonomic nervous system dysregulation, but neither Hirschsprung's disease nor signs suggestive of a malignant tumor of the sympathetic nervous system. Regarding the functional relevance of the missense mutation for the phenotypical presentation, we have several arguments supporting this hypothesis. First of all, neither the older brother nor the biologically identified parents have the very mutation of our index patient. Second, missense mutations in the PHOX2B gene are known to decrease transactivation of the dopamine beta hydroxylase promotor, can lead to aggregate formation, and can result in mislocalization of the protein in the cytoplasm (Trochet et al. 2005). All these mechanisms could affect function and potentially result in complete loss-of-function. Third, the PolyPhen database (http://www.bork.embl-heidelberg. de/PolyPhen) has classified our substitution of amino acids (Gly68Cys) as 'possibly damaging'; the Grantham score of 159 is additionally suggestive of an effect on protein function. Fourth, glycin in position 68 is a highly conserved amino acid across species (Table 1), which 
Table 1 Fragment of multiple alignment around aminoacid position 68 of PHOX2B (arrow)

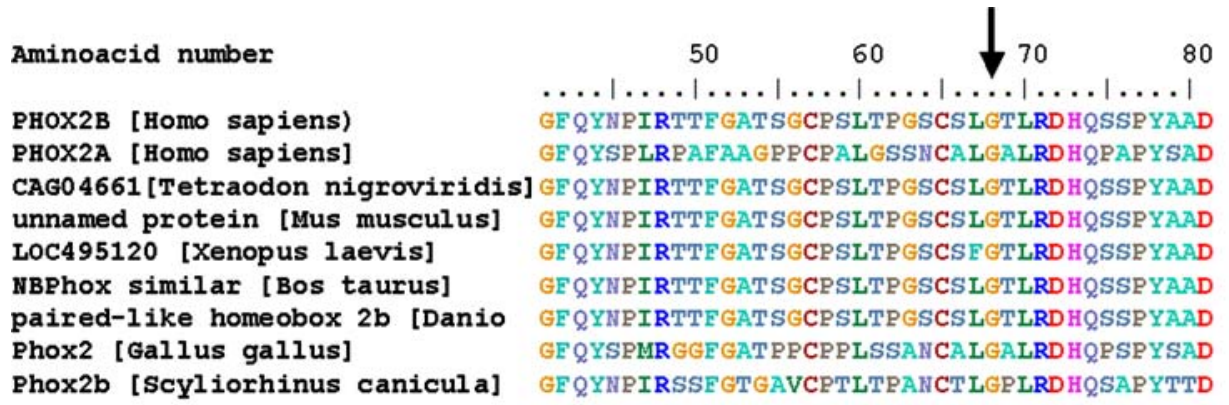

Fragment of multiple alignment around aminoacid position 68 of PHOX2B (arrow)

increases the likelihood of impaired function of the protein with any substitution of this amino acid.

Furthermore, our patient is the third CCHS patient also presenting with hyperinsulinism. In both other patients (Meissner et al. 2001), a polyalanin repeat mutation was the underlying cause (alanin expansion +6 and +7 , respectively). Laboratory parameters on initial presentation were as follows: patient A: insulin $8.5 \mathrm{mU} / \mathrm{l}$, glucose $1.8 \mathrm{mmol} / \mathrm{l}$, ratio insulin/glucose: 4.7 ; patient $\mathrm{B}$ : insulin $20.8 \mathrm{mU} / \mathrm{l}$, glucose $2.0 \mathrm{mmol} / \mathrm{l}$, ratio insulin/glucose: 10.4 . Since different types of mutation are present in these three patients with CCHS and hyperinsulinism, this rare clinical feature of CCHS is unlikely to be associated with either polyalanin or nonpolyalanin mutations. Regarding these three cases, it appears impossible to establish any kind of correlation between extent and duration of hyperinsulinemia and the underlying mutation. However, hyperinsulinism may be linked to CCHS and could represent an additional clinical feature of this complex disease.

CCHS without associated diseases like Hirschsprung's disease is difficult to diagnose in preterm infants as a result of prematurity-associated apnea and bradycardia. Clinical suspicion, additional symptoms like autonomic nervous system dysregulation, hyperinsulinism, and ultimately testing for PHOX2B mutation can confirm the diagnosis. Mutation testing may also help to predict progression of the disease and allows genetic counselling of affected parents. Management of this rare disease presenting in a preterm infant is challenging due to the overlap with specific problems of prematurity, the prognosis of CCHS presenting early in infancy is limited.

\section{References}

Ahren B (2000) Autonomic regulation of islet hormone secretionimplications for health and disease. Diabetologia 43:393-410

Amiel J, Laudier B, Attie-Bitach T, Trang H, de Pontual L, Gener B, Trochet D, Etchevers H, Ray P, Simonneau M, Vekemans M, Munnich A, Gaultier C, Lyonnet S (2003) Polyalanine expansion and frameshift mutations of the paired-like homeobox gene PHOX2B in congenital central hypoventilation syndrome. Nat Genet 33:459-461

Bajaj R, Smith J, Trochet D, Pitkin J, Ouvrier R, Graf N, Sillence D, Kluckow M (2005) Congenital central hypoventilation syndrome and Hirschsprung's disease in an extremely preterm infant. Pediatrics 115:e737-e738

Berry-Kravis EM, Zhou L, Rand CM, Weese-Mayer DE (2006) Congenital central hypoventilation syndrome: PHOX2B mutations and phenotype. Am J Respir Crit Care Med 174:1139-1144

Croaker GD, Shi E, Simpson E, Cartmill T, Cass DT (1998) Congenital central hypoventilation syndrome and Hirschsprung's disease. Arch Dis Child 78:316-322

Dubreuil V, Hirsch MR, Pattyn A, Brunet JF, Goridis C (2000) The Phox $2 b$ transcription factor coordinately regulates neuronal cell cycle exit and identity. Development 127:5191-5201

Dubreuil V, Hirsch MR, Jouve C, Brunet JF, Goridis C (2002) The role of Phox $2 b$ in synchronizing pan-neuronal and type-specific aspects of neurogenesis. Development 129:5241-5253

Matera I, Bachetti T, Puppo F, Di Duca M, Morandi F, Casiraghi GM, Cilio MR, Hennekam R, Hofstra R, Schober JG, Ravazzolo R, Ottonello G, Ceccherini I (2004) PHOX2B mutations and polyalanine expansions correlate with the severity of the respiratory phenotype and associated symptoms in both congenital and late onset Central Hypoventilation syndrome. J Med Genet 41:373-380

Meissner T, Rabl W, Mohnike K, Scholl S, Santer R, Mayatepek E (2001) Hyperinsulinism in syndromal disorders. Acta Paediatr 90:856-859

Palladino AA, Bennett MJ, Stanley CA (2008) Hyperinsulinism in infancy and childhood: when an insulin level is not always enough. Clin Chem 54:256-263

Rohrer T, Trachsel D, Engelcke G, Hammer J (2002) Congenital central hypoventilation syndrome associated with Hirschsprung's disease and neuroblastoma: case of multiple neurocristopathies. Pediatr Pulmonol 33:71-76

Ste Marie L, Palmiter RD (2003) Norepinephrine and epinephrinedeficient mice are hyperinsulinemic and have lower blood glucose. Endocrinology 144:4427-4432

Stornetta RL, Moreira TS, Takakura AC, Kang BJ, Chang DA, West GH, Brunet JF, Mulkey DK, Bayliss DA, Guyenet PG (2006) Expression of Phox $2 b$ by brainstem neurons involved in chemosensory integration in the adult rat. $J$ Neurosci 26:10305-10314

Trochet D, O'Brien LM, Gozal D, Trang H, Nordenskjold A, Laudier B, Svensson PJ, Uhrig S, Cole T, Niemann S, Munnich A, Gaultier C, Lyonnet S, Amiel J (2005) PHOX2B genotype allows for prediction of tumor risk in congenital central hypoventilation syndrome. Am J Hum Genet 76:421-426 
Weese-Mayer DE, Berry-Kravis EM (2004) Genetics of congenital central hypoventilation syndrome: lessons from a seemingly orphan disease. Am J Respir Crit Care Med 170:16-21

Weese-Mayer DE SD, Keens TG, Silvestri JM (1999) Idiopatic congenital central hypoventilation syndrome: diagnosis and management. Am J Resp Crit Care Med 60:368-373

Weese-Mayer DE, Berry-Kravis EM, Zhou L, Maher BS, Silvestri JM, Curran ME, Marazita ML (2003) Idiopathic congenital central hypoventilation syndrome: analysis of genes pertinent to early autonomic nervous system embryologic development and identification of mutations in PHOX2b. Am J Med Genet A 123:267-278

Zhu MY, Wang WP, Iyo AH, Ordway GA, Kim KS (2005) Ageassociated changes in mRNA levels of Phox2, norepinephrine transporter and dopamine beta-hydroxylase in the locus coeruleus and adrenal glands of rats. J Neurochem 94:828-838 